GRANTEE: $\quad$ CALIFORNIA INSTITUTE OF TECHNOLOGY

Division of Geological and Planetary Sciences

Pasadena, CA 91125

GRANT: $\quad$ DE-FG03-88ER13851

TITLE: Isotope Tracer Studies of Diffusion in Silicates and of Geological Transport Processes Using Actinide Elements

PRINCIPAL G. J. Wasserburg (626) 395-6139; FAX (626) 796-9823

INVESTIGATOR: E-mail: isotopes@gps.caltech.edu

Objectives: The initial aims of this project have not been modified.

Project Results: Over the past year we have competed two studies of Os concentration and isotopic composition in rivers from the Himalayan uplift and in hydrothermal fluids from the Juan de Fuca Ridge. Both of these studies have been published. We have completed a study of paleo-climate in Soreq Cave, Israel, and have expanded our studies of the transport of U-Th through riverine and estuarine environments. We are completing two studies of weathering and transport in the vadose in two very different environments - one a tropical regime with a deep laterite profile and the other a northern arboreal forest with only a thin weathering zone. We have begun a new study of U-Th in aquifers with low water velocity.

1) The first of the Os papers (Sharma et al. 1999) demonstrated that the major rivers draining the Himalayan uplift cannot be responsible for the increase in ${ }^{187} \mathrm{Os} /{ }^{188} \mathrm{Os}$ over the past $20 \mathrm{Ma}$. It was also argued that a Himalayan source for the ${ }^{87} \mathrm{Sr} /{ }^{88} \mathrm{Sr}$ increase with time over this period. These results are in strong contrast with the claims that the principle cause of shift in seawater has been due to weathering from the Himalayas. Instead, it is argued that global changes in climate and weathering (possibly associated with the Himalayan uplift) is the cause of the increase in ${ }^{187} \mathrm{Os} /{ }^{188} \mathrm{Os}$ and ${ }^{87} \mathrm{Sr} /{ }^{88} \mathrm{Sr}$ with time. This challenge to the much exercised Himalayan weathering model now must be subject to other tests.

2) The study of hydrothermal springs represent the first set of Os measurements on mantle sources contributing non-radiogenic Os to the oceans. This work unambiguously shows that there is mantle-type Os injected into seawater at spreading centers, but that the amounts are orders of magnitude too small to account for the low ${ }^{187} \mathrm{Os} /{ }^{188} \mathrm{Os}$ value in seawater. It is argued that low-temperature, off-ridge fluids are responsible for the input of mantle Os and Sr. (Sharma et al., 2000).

3) A study of paleo-climate in the Eastern Mediterranean was led by M. Bar-Matthews. This was a most complete and informative study of $\mathrm{C}$ and $\mathrm{O}$ isotopic variation as a function of time during the last 60,000 years. This study completes the work that we have been doing on the Soreq cave. Further studies will be carried out on other caves by other groups in Israel to pursue the climate problem more extensively. (Bar-Matthews et al. 1999)

4) A study was made by Andersson et al. (2001) on the transport of uranium isotopes into the 
marine environment. This work has been most successful and clearly identifies the role of particles and colloids in the removal of $U$ from riverine input, and the exchange with the large $U$ reservoir in seawater. The study is accepted for publication and will appear shortly.

5) The investigation of both long-lived and short-lived nuclei in the U-Th series (including ${ }^{230} \mathrm{Th}$ ) was carried out in rivers, bogs and the estuarine environment. This study focused on the transport from a continental source region, through bogs, to rivers and finally to the estuarine environment. Surprisingly, it was found that bogs with extremely high $U$ concentrations did not have a major role in the chemistry and radio-isotope concentration in run-off or in rivers.

6) Two studies on weathering and transport in the vadose zone were carried out. The first of these was in a tropical regime (Cameroons) with a very deep laterite profile and the other was in a northern arboreal forest (Sweden) with only a thin weathering zone. The first study was sufficiently complete (Viers et al.) and a draft manuscript has already been prepared. It should be completed in the next four months. This is unfortunately slow because the study scientist has returned to a professorial position in France.

7) A new project has been initiated with Dr. Ben Reynolds, who has recently joined the group. This project involves a study of U-Th series nuclides in aquifers with low water velocity. A first study has begun on an aquifer in northern New Mexico that had previously been studied for ${ }^{14} \mathrm{C}$ and He. Reynolds is now in the field collecting samples.

8) A new postdoctoral fellow, C.-T. Lee from Harvard will be arriving and starting work on 1 March 2001.

\section{LIST OF APPENDED PAPERS}

Andersson PS, Porcelli D, Gustafsson O, Ingri J, and Wasserburg GJ. (2001) The importance of colloids for the behavior of uranium isotopes in the low salinity zone of a stable estuary. Geochim. Cosmochim. Acta,in press.

Bar-Matthews M, Ayalon A, Kaufman A, Wasserburg GJ, and Ghalib B. (1999) Eastern Mediterranean paleoclimate during the last 60,000 years as derived from speleothems, Soreq Cave, Israel. Earth Planet. Sci. Lett. 166, 85-95.

Land M and Wasserburg GJ (in preparation) Mobility and transport of Nd isotopes in the vadose zone during weathering of a granitic till in a boreal forest.

Porcelli D, Andersson PS, Baskaran M, and Wasserburg GJ. (2001) The transport of U- and Th-series nuclides in a Baltic Shield Watershed and the Baltic Sea. Geochim. Cosmochim. Acta, in press.

Sharma M, Wasserburg GJ, Hofmann AW, and Butterfield DA (200) Osmium isotopes in hydrothermal fluids from the Juan de Fuca Ridge. Earth Planet. Sci. Lett. 179, 139-152. 
Sharma M, Wasserburg GJ, Hofmann AW, and Chakrapani GJ (1999) Himalayan uplift and osmium isotopes in oceans and rivers. Geochim. Cosmochim. Acta 63, 4005-4012.

Tricca A, Porcelli D, and Wasserburg GJ (1999) Factors controlling the groundwater transport of U, Th, Ra, and Rn. Indian Academy of Science (Earth Planet. Sci.) 109, 95-108.

Viers J, Chen JH, Wasserburg GJ (in preparation) $\mathrm{Sm}-\mathrm{Nd}$ and $\mathrm{U}$ isotopes in two laterites from the Cameroons, Africa. 